\title{
Teaching SAP's ABAP Programming Language to IS Students: Adopting and Adapting Web-based Technologies
}

\author{
Brendan McCarthy and Paul Hawking \\ Victoria University, Melbourne, Australia
}

\section{Brendan.McCarthy@vu.edu.au Paul.Hawking@vu.edu.au}

\begin{abstract}
This paper describes the experiences of Victoria University in adopting and adapting web-based technology to enhance the teaching of SAP's ABAP programming language. The involvement of SAP relates to Victoria University integrating Enterprise Resource Planning (ERP) systems into their curricula and research programs through a strategic alliance with SAP. The SAP technical infrastructure facilitates the development of courses using Internet technology and has particular suitability to the teaching of programming.
\end{abstract}

This paper describes the Web-based technologies used and how they have been adapted to improve both the teaching of programming and management of assessment. Each technology is discussed and advantages identified with possible future research developments put forward.

Keywords: Computer Programming, Enterprise Resource Planning Systems, SAP, ABAP, Internet, Web technologies.

\section{Introduction}

There have been a number of studies, which have attempted to identify Information Systems (IS) graduate skills and the resultant curriculum. The IS'97 Model Curriculum and the more recent revised curriculum IS2002 (Davis et al 1997) was a collaborative development between industry and academia. The model provided guidelines and resources to facilitate the development of quality undergraduate IS curriculum. An important component of both curricula is computer programming and the structures involved.

Computer programming still remains an important part of most Information Systems courses. However the emphasis today is on teaching programming concepts and style and using programming languages to support this objective. Most IS courses include an introductory subject on basic programming concepts and basic problem solving. Educationalists believe that the language chosen should be based on its ability to convey enduring concepts and to demonstrate fundamental programming techniques (Johnson, 1995).

Once students have grasped a basic understanding of programming concepts and techniques, such skills can be used as a basis to learning application development in its various guises from developing database applications using SQL to designing web applications using Java.

The Information Systems discipline has a business focus where information systems requirements are

Material published as part of these proceedings, either on-line or in print, is copyrighted by Informing Science. Permission to make digital or paper copy of part or all of these works for personal or classroom use is granted without fee provided that the copies are not made or distributed for profit or commercial advantage AND that copies 1) bear this notice in full and 2) give the full citation on the first page. It is permissible to abstract these works so long as credit is given. To copy in all other cases or to republish or to post on a server or to redistribute to lists requires specific permission from the publisher at publister@intormingscience.org matched to an organization's objectives. It is important for students to realise the link between organizational objectives and application development, and IS curriculum should reflect this link. It is often difficult to extend a student's basic knowledge of programming techniques into a business setting. Providing a business environment would allow students to apply and extend their algorithm 
Teaching SAP's ABAP Programming Language

and problem solving techniques, however such environments are not usually available to university students. We believe that our students' experience of learning programming in the SAP R/3 environment enhances their knowledge of business requirements.

SAP R/3 is a type of software classified as Enterprise Resource Planning (ERP) Systems software. ERP systems offer a solution that handles an enterprise's total information system needs in an integrated fashion. Such systems have seen a tremendous growth in the last decade in the US, Europe and Australian markets with emerging growth in the Asian region.

SAP is the leading ERP vendor with 30 percent of the market. Oracle and PeopleSoft follow with 14 and 7 percent, respectively (Gilbert 2000). SAP is the largest client/server and mainframe ERP software vendor. Approximately 350 companies in Australia use SAP. SAP has formed partnerships with universities around the world and part of that arrangement is the free provision of their software to universities for inclusion into their curriculum.

SAP R/3 incorporates its own unique programming language called ABAP. ABAP is an event-driven fourth-generation language. It is a language that is constantly evolving with recent releases incorporating object-oriented capabilities (ABAP objects). The robustness of the language is evident in the wide range of functionality and high performance capabilities within the R/3 system, allowing applications to process huge amounts of customer data (Kretschmer and Weiss, 1996). SAP R/3 provides an environment rich in tools for developing business applications using the ABAP programming language.

While ABAP is not one of the universally used programming languages like $\mathrm{C}$ or Java, it is an excellent language to extend students comprehension of programming concepts in a powerful business environment. Thus it is ideally suited to IS students.

\section{Features of ABAP}

A number of features make ABAP a suitable language for students to learn programming concepts and develop programming skills. These features include:

- Embedded in the language is a subset of Structured Query Language (SQL) called Open SQL. Open SQL and the database interface of the R/3 system form layers between the Database Management System and the application program. This layered architecture enables the developer to concentrate on conceptual aspects rather than worry about things like memory management, pointer arithmetic or network issues (Kretschmer and Weiss, 1996).

- The language links to an integrated Data Dictionary containing type definitions and data structures that the developer can use in all programs. The Dictionary contains over 8000 table definitions, most related to the business modules of the SAP system. SAP provides development models to assist programmers understand concepts and develop skills. These models are realistic business models with the relevant database tables populated with huge amounts of realistic data. For example, the bookings table in the Airline Reservations model contains more than 53,000 records.

- The language is event-driven; that is, user actions and system events control the application's execution. Thus developers can develop complex interactive programs that support "drill-down" events.

- The language provides two techniques for defining subroutines: local and global. Global subroutines, called Function Modules, are stored in a central library and available to all programs. They use a standard interface for passing parameters and exemption handling. The Function Module library has efficient searching tools allowing developers to find appropriate modules to incorporate into their programs. SAP R/3 4.6 comes with over 98,000 Function Modules.

- The language uses the concept of internal tables, which provide a consistent mapping of persistent database tables into runtime objects. For example, the contents of a database table can be mapped into an 
internal table at runtime, so that the internal table is a snapshot of the database table itself (Kretschmer and Weiss, 1996).

- The language supports structured programming techniques.

SAP R/3 provides the "ABAP Workbench" containing a repository of development tools. These tools provide the developer with a range of functionality that covers the entire software development cycle (Refer to Figure 1).

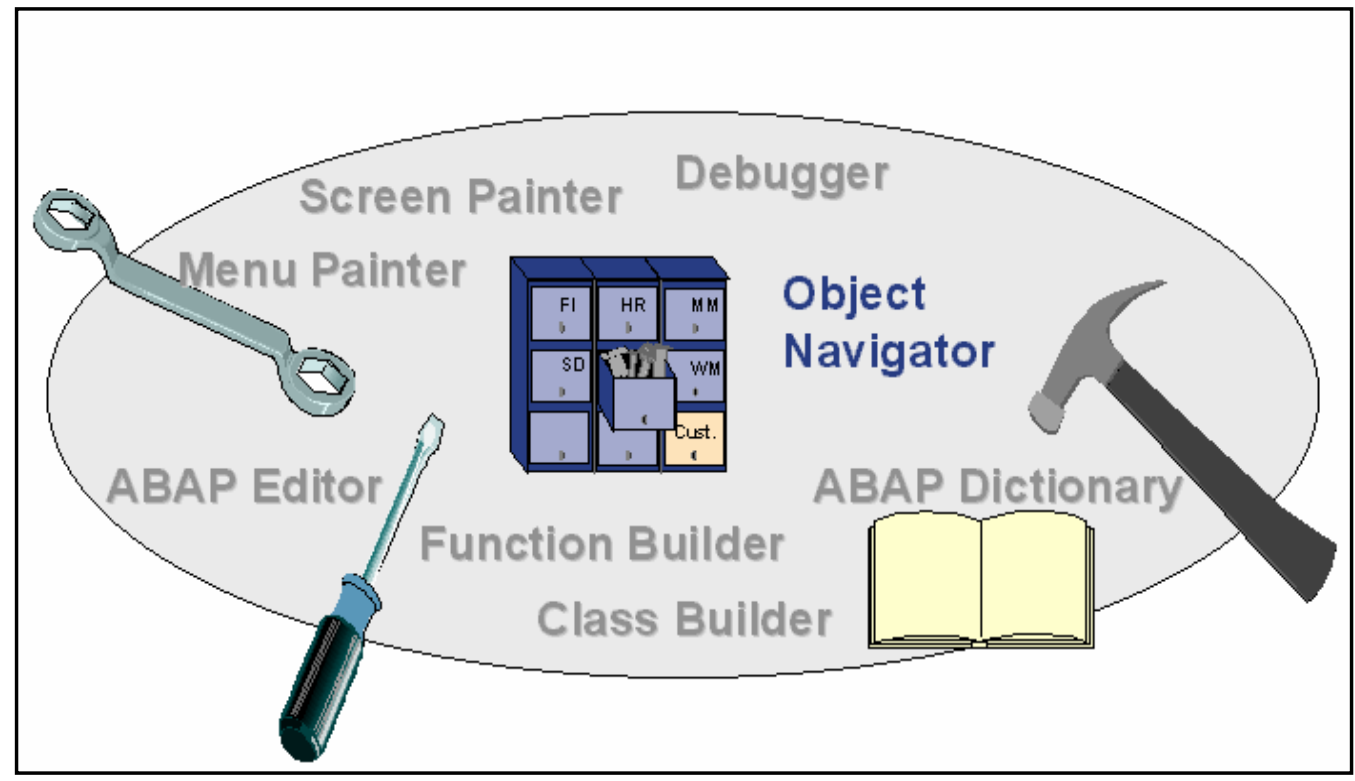

Figure 1: ABAP Workbench Tools (SAP Training Notes)

The most important tools for developing business applications are:

- ABAP Editor for writing and editing program code;

- ABAP Dictionary for processing database tables and retrieving global data;

- Menu Painter for designing the user interface (menu bar, standard toolbar, application toolbar);

- Screen Painter for designing screens (dynamic or screen programs) for user dialogs;

- Function Builder for displaying and processing function modules (subroutines with defined interfaces that are available throughout the system);

- Class Builder for displaying and processing central classes (Object-oriented objects)

The ABAP programming language supported by the SAP R/3 system is ideally suited to IS students to extend their understanding of programming concepts in a powerful business environment that cannot be matched with the environments made available in other programming languages.

\section{ABAP at Victoria University}

ABAP was integrated into two programming subjects in 1999, one at undergraduate level and the other at postgraduate level. Since its introduction the numbers of students enrolled in both subjects has remained consistently high. One interesting observation is that each semester, on average, 10 per cent of enrolled students come from outside the School of Information Systems. Many are from the Faculty of Computer Science and we also have had a small number of students who enrol while undertaking studies from other universities. Refer to Table 1 for a summary of ABAP enrolments for 1999 to 2002. 
Teaching SAP's ABAP Programming Language

\begin{tabular}{|l|r|r|r|}
\hline \multicolumn{4}{|c|}{ ABAP Enrolments 1999 - 2002 } \\
\hline & $\begin{array}{r}\text { Undergraduate } \\
\text { Subject }\end{array}$ & $\begin{array}{r}\text { Postgraduate } \\
\text { Subject }\end{array}$ & Total \\
\hline 1999 & 156 & 88 & 244 \\
\hline 2000 & 147 & 72 & 219 \\
\hline 2001 & 122 & 73 & 195 \\
\hline 2002 & 49 & 46 & 95 \\
Semester 1 only & 474 & 20 & 20 \\
\hline 2002 - Singapore & & 299 & 773 \\
\hline \hline Total & & & \\
\hline \hline
\end{tabular}

Table 1: Summary of ABAP enrolments 1999-2002

Assessment in both subjects is quite challenging with 3 practical assignments and two exams, one theory and the other practical. In addition the postgraduate students are required to do a research assignment on programming language development.

The consistently high enrolments indicate that this subject is quite popular. Student evaluations at the end of each semester support this. The massive resources provided by ABAP and the SAP R/3 environment is recognised by students as a valuable industry setting to develop their programming skills.

\section{Web-based Technologies}

Teaching a programming language such as ABAP in the SAP R/3 environment does present both teaching staff and students with a number of difficulties. For staff there is the requirement for training, the long timeline for curriculum development and the management of student accounts and assessment. Not all these staff issues are addressed in this paper. For students there are the difficulties of gaining SAP access and the initial learning curve in working in the SAP environment.

We have addressed some of these issues by making use of some web-enabled technologies, which I will outline below.

\section{Application Service Provision}

An Application Service Provider is a third party service provider that supplies organizations with a complete solution to their computing needs (Robinson, 2000). Application Service Provision (ASP) is a technology that provides the necessary technological infrastructure and support to host a particular software product. This enables the clients of the ASP to remotely access the software via the Internet. One of the barriers for our students was accessing our SAP system outside university class times and the university environment. The ASP model combined with the infrastructure of the Internet provides a solution to overcoming this barrier.

Victoria University has configured one of its SAP servers to support the role of an ASP and provide access to SAP, not only to local students but also students enrolled in our offshore program running in Singapore. Students can access the SAP software via the Internet once they have installed the SAPgui software on their local PC's. This means students can access SAP at their leisure to work on programming exercises and assignments without the need to physically attend the university computer laboratories. 


\section{Synchronous E-learning}

There is a growing trend amongst academics to use the Internet to increase access to educational materials in a variety of ways to support the learning process (Pather and Erwin 2000). The ASP enables access to the SAP system while the Synchronous E-learning technology provides access to the curriculum. The Centra Corporation has developed such technology. They have developed a suite of compatible, real-time Web collaboration products, content creation tools, and knowledge delivery systems. The Synchronous Elearning technology is Internet based and allows the two-way delivery of education in real time. Students are able to log into a virtual classroom based at Victoria University. They hear the lecturer's voice in real time while viewing lecturer controlled slides on their screens. If a student has a query, they can "alert" the lecturer via the Synchronous E-learning tool and the lecturer can then appropriately respond to the query. This two-way communication facilitates the interaction between the lecturer and student thus enhancing the learning process.

The technology allows lecturers to teach the necessary programming concepts and then demonstrate these concepts using the SAP system via the Synchronous E-learning technology. The lecture can also be recorded and replayed at a later stage, however this option does not support the advantages of two-way interaction. Once students have completed the lecture they can access the SAP system via the ASP to practice programming concepts that were covered in the lecture. This technology is most suited to distance learning and is being trailed this year in our offshore program running in Singapore.

\section{Web $C T$}

Web CT is a web-based tool used as a single point of entry for students to access online material and media. It is used to supplement face-to-face teaching. The tool allows students to view and download subject outlines, assignments, past examination material and lectures and to execute e-learning modules. Students can submit assignments via the tool and then view their results once the assignments have been marked. Teaching staff can interact with students via a discussion board and chat facilities to enable students to discuss set tutorial questions and discuss issues they have encountered. Staff can also communicate with students by direct email links and global email facilities.

\section{iTutor}

This tool is used for developing interactive tutorials in a simulated SAP environment. It is an SAP product and we are able to use it as a result of the SAP University Alliance. iTutor enables the lecturer to record an action or programming sequence within the SAP environment and capture the screens involved to form the basis of a tutorial. After recording the tutorial, the iTutor Editor is used to edit the structure of the tutorial, define alternative paths, edit instructional texts and create additional supplementary descriptive texts. This facility allows educational concepts to be inserted into tutorials using tools such as PowerPoint. The computer-based tutorials enable students to combine programming theoretical concepts with the appropriate SAP ABAP screens and actions.

iTutor is a highly interactive teaching tool encouraging user involvement thereby increasing the learning retention rate. It can complement instructor-led education and is also suited to distance learning environments. Students can replay the tutorial as many times as necessary to understand demonstrated concepts.

iTutor lessons are placed on Web CT allowing enrolled students to execute these tutorials once they lave logged in. The Synchronous E-learning technology can be used for plenary sessions to reinforce the concepts covered and answer any questions coming out of the iTutor tutorials.

This tool has the added benefit of capturing and storing a lecturer's knowledge that can then be reused by others at a later stage either in a different subject or to assist if the lecturer is no longer available. 


\section{Conclusion}

The four web-based/web-enabled technologies outlined above are not unique but combining these technologies to supplement the teaching of ABAP in an SAP environment does address some of the barriers facing students coming into this programming subject. They provide an avenue for learning programming concepts and techniques using a variety of methods to cater for students' differing needs and learning styles and given the rather complex nature of the SAP environment.

We are trialling these technologies both locally and offshore. If this trial proves successful we plan to extend our initiatives by applying these technologies to other SAP-related subjects, other IS subjects and other offshore partners.

\section{References}

Davis, G., et al., (1997), IS'97: Model Curriculum and Guidelines for Undergraduate Degree Programs in Information Systems, ACM and AITP: USA.

Gilbert, A., (2000). "ERP vendors look for rebound after slowdown”, Informationweek News, 14 February 2000.

Johnson L. F., (1995). "C in the first course considered harmful”, Communications of the ACM, May 1995, Vol. 38 No 5, pg. 99(3).

Kretschmer, R. \& Weiss, W., (1996). Developing Sap's R/3 Applications With Abap/4, Sybex, 1996.

Pather, S. and Erwin, G. (2000). "Issues and Challenges for Web Based Course Delivery in the South African Tertiary Education Context." Published in the proceedings SAICSIT-2000, Cape Town, November 2000.

Robinson, D., (2000). “ASP As Soon As Possible”, People Management, 13 April 2000, Vol. 6 Issue 8, pg. 51.

\section{Biographies}

Paul Hawking is a lecturer in the School of Information Systems at Victoria University, Melbourne, Australia. He is the SAP Academic Program Director for the Faculty of Business and Law and is responsible for the facilitation of ERP education across the university. He has been involved in education delivery and curriculum development for the past twenty years and has co-authored a series of computer texts. He is currently Chairperson of the Australian SAP User Group.

Brendan McCarthy is also a lecturer in the School of Information Systems at Victoria University, Melbourne, Australia. He is the program co-ordinator of the Master of Business in Enterprise Resource Planning Systems. He has been involved in education delivery and curriculum development for the past twenty-five years and has co-authored of a series of computer texts. 